\title{
Sobre el espíritu en Hegel y Edith Stein ${ }^{1}$
}

\author{
Luis Mariano de la Maza \\ INSTITUTO DE FILOSOFÍA \\ PONTIFICIA UNIVERSIDAD CATÓLICA DE CHILE \\ sdel4@uc.cl
}

Resumen: El concepto de espíritu es central en el pensamiento filosófico de Hegel y Edith Stein. En los dos tiene una común raíz y cristiana y ambos lo consideran como lo que define esencialmente al ser humano. Además, afirman que lo propio del espíritu no se reduce a la capacidad de conocer o de razonar, sino que implica también la capacidad de superar los límites de su finitud y abrirse al otro, que incluye a otros seres espirituales finitos, pero sobre todo al espíritu infinito, el Absoluto o Dios. No obstante, existen también entre ambas concepciones importantes diferencias en el modo como se refieren a la relación entre espíritu y naturaleza, a la relación entre libertad e historia, y al sentido del Estado y su rol respecto de la moral.

Palabras clave: Espíritu, autoconciencia, libertad, formación, historia, Estado, religión

Abstract: The concept of spirit is central in Hegel's and in Edith Stein's philosophy. They have a common root in Christianity, and both consider that spirit defines human being essentially. They claim, moreover, that spirit cannot be reduced to the ability to know or to reason, but also implies the ability to overcome the limits of its finiteness and open oneself to the other, which includes finite spiritual beings, but especially the infinite Spirit, the Absolute or God. However there are also important differences between both conceptions concerning the relationship between spirit and nature and between freedom and history, and also about the meaning of the State regard to moral life.

Keywords: Spirit, self-consciousness, freedom, formation, history, state, religion.

1 Este artículo corresponde a la versión ampliada de una ponencia realizada en el Simposio Internacional "La formación de la persona humana. Fundamentos antropológicos, filosóficos y teológicos de la educación en Edith Stein”, organizado por el Centro de Investigación Interdisciplinaria Edith Stein en la Facultad de Teología de la Pontificia Universidad Católica de Chile, entre los días 12-14 de agosto de 2014. 


\section{INTRODUCCIÓN}

Exponer la filosofía del espíritu en uno solo de los dos autores mencionados en el título de este artículo plantea un desafío muy difícil de realizar, porque para ambos constituye un eje central de su pensamiento, que se extiende a todas las dimensiones de sus respectivas obras. Ocuparse de los dos es una tarea prácticamente imposible, a menos que el tema se circunscriba solo a algunos de los aspectos que se reconozcan como los más aptos para establecer una comparación, aunque no se disponga del espacio para examinarlos con la profundidad que merecen. Por lo tanto, se abordarán de modo elemental temas que giran en torno al concepto del espíritu, a las estructuras de la autoconciencia y la libertad, a la formación del espíritu y a sus dimensiones comunitaria, histórica y religiosa. Una segunda restricción es que, salvo alguna contada excepción, como la Fenomenología del espiritu de Hegel o la Investigación sobre el Estado de Edith Stein, la exposición se concentrará en la obra madura de ambos.

El sentido de esta comparación, o el interés filosófico que la anima, se conecta con el problema más amplio de la relación entre filosofía y religión. La cuestión religiosa se aborda, por lo tanto, en un doble respecto. Por un lado es un aspecto o dimensión particular de las concepciones del espíritu que se van a contrastar. Pero por otro lado es sobre todo un presupuesto común, que en ambos pensadores permea indiscutiblemente su modo de hacer filosofía y el contenido de la misma, de lo que da cuenta justamente la importancia que le atribuyen al tema del espíritu. Tanto Hegel como Edith Stein se reconocen a sí mismos como deudores de la tradición judeocristiana. La pregunta que se plantea es, entonces, en qué medida, y de qué formas, esa raíz común admite, desde el punto de vista de su elaboración filosófica, respuestas que no solo tienen coincidencias, sino también importantes divergencias, mediante las cuales queda en evidencia que la referencia a la base cristiana no inhibe ni obstaculiza la posibilidad de un pensar libre, sometido a criterios racionales que no conducen necesariamente a los mismos resultados, y que merecen ser tomados igualmente en serio en un proceso honesto de búsqueda de la verdad teórica y práctica sobre la realidad del hombre y de Dios.

\section{EL CONCEPTO DE ESPÍRITU}

En Estructura de la Persona Humana, Edith Stein analiza el concepto de espíritu contrastando el término alemán Geist con tres expresiones latinas 
a las que se puede traducir sin reducirse a ninguno de ellos en particular: intellectus, mens y spiritus ${ }^{2}$. Intellectus designa el aspecto cognoscente del espíritu, el intelecto, que suele ser contrapuesto a la voluntad o al corazón del hombre; mens, por su parte, se usa habitualmente en un sentido más amplio para referirse a la mente como parte superior o racional del alma humana, que abarca tanto la inteligencia como la voluntad, y que entonces se contrapone a la sensibilidad en tanto que parte inferior del alma. Los dos casos anteriores designan una parte del alma humana, no su totalidad. En cambio spiritus se refiere al alma en su conjunto, pero enfrentada ahora al cuerpo, en tanto que realidad material o extensa, no viviente. Este último sentido de espíritu, que es el que Stein hace suyo, equivale al griego pneuma, el cual apunta a la ligereza o falta de fijación del espíritu, es decir, al hecho de que no está atado, como las cosas materiales, a una figura inamoviblemente delimitada, sino que se mueve libremente, como el hálito o el viento que sopla en cualquier dirección.

El concepto hegeliano de espíritu también se refiere a una totalidad, pero es un todo que no se contrapone a la naturaleza material, sino que se identifica con ella al mismo tiempo que la supera. Lo propio del espíritu es para Hegel negar todo lo finito y limitado, pero sin destruirlo, sino conservándolo en un nivel superior que integra esas realidades limitadas como momentos complementarios (Aufhebung). Esta actividad presupone un continuo diferenciarse de sí mismo que retorna una y otra vez a una identidad cada vez más elevada y compleja.

El espíritu solo tiene su realidad efectiva si se escinde en sí mismo, se da un límite y finitud en las necesidades [Bedürfnisse] naturales y en la conexión de esa necesidad [Notwendigkeit] exterior, y penetrando en ellas se forma, las supera y conquista así su existencia objetiva ${ }^{3}$.

2 E. Stein, Der Aufbau der menschlichen Person. Vorlesung zur philosophischen Anthropologie, en Gesamtausgabe (ESGA) Herder, Freiburg i. B./Basel/ Wien 1998-, XIV, 99 s.; "Estructura de la persona humana" (EPH), en Obras completas IV, Ediciones el Carmen/Editorial de Espiritualidad/Editorial Monte Carmelo, Vitoria/Madrid/Burgos 2002-, 673 s.

3 "Der Geist hat seine Wirklichkeit nur dadurch, dass er sich in sich selbst entzweit, in den Naturbedürfnissen und in dem Zusammenhange dieser äusseren Notwendigkeit sich diese Schranke und Endlichkeit gibt und eben damit, dass er sich in sie hineinbildet, sie überwindet und darin sein objektives Dasein gewinnt". Georg Wilhelm Friedrich Hegel, Grundlinien der Philosophie des Rechts oder Naturrecht und Staatswissenschaft im Grundrisse. Mit Hegels eigenhändigen Notizen und den mündlichen Zusätzen. En Werke in zwanzig Bänden (Werke). Redaktion 
El espíritu no es algo acabado, sino que se realiza a sí mismo en y por las distintas formas que adquiere en su automanifestación. En tanto que actividad autoconstituyente es sujeto, pero también es objeto, porque su autorrealización se da en la relación con lo otro de sí, a lo que supera en su alteridad e integra en su propio ser, reconociéndolo como un momento de sí mismo. En este sentido, el portador último del espíritu es el ser infinito, el Absoluto o Dios, puesto que no puede haber nada que le sea exterior, poniéndole límites insuperables.

El presupuesto básico del espíritu es para Hegella naturaleza ${ }^{4}$. Sin naturaleza no hay espíritu. Pero el espíritu es la verdad de la naturaleza, en la que esta es superada, transformándose en vida que se relaciona reflexivamente consigo misma mediante la inteligencia y la voluntad (espíritu subjetivo); y que luego se despliega en el mundo de las formaciones culturales, costumbres e instituciones históricas (espíritu objetivo) para alcanzar finalmente su máxima realización en el conocimiento de sí mismo como espíritu absoluto a través del arte, la religión y la filosofía ${ }^{5}$.

En Edith Stein el espíritu se refiere esencialmente al concepto de la persona, entendida como el soporte (suppositio) de una naturaleza dotada de razón y caracterizada por su capacidad de referirse a sí misma y configurar su comportamiento, por su apertura a las cosas distintas de sí y por la capacidad de elevarse por encima de sí. Esta triple apertura del espíritu justifica que Edith Stein distinga en forma semejante, aunque no igual a la de Hegel, entre espíritu subjetivo, objetivo y divino. La principal diferencia en este punto es que la tripartición no se refiere a un proceso de progresiva realización del espíritu, sino más bien a los tres ámbitos hacia los que dirige su actividad: la propia interioridad del alma, las creaciones culturales, valores e instituciones sociales, y Dios o la vida sobrenatural ${ }^{6}$.

Eva Moldenhauer und Karl Markus Michel, Suhrkamp, Frankfurt 1969-1971, VII; Principios fundamentales de la filosofía del derecho (FD). Traducción. de J. L. Vermal, Ed. Sudamericana, Buenos Aires 2004, \$187, Obs.

4 G.W.F. Hegel, Enzyklopädie der philosophischen Wissenschaften im Grudrisse (1830). Hrsg. von Friedhelm Nicolin und Otto Pöggeler. Meiner, Hamburg 1969; Enciclopedia de las ciencias filosóficas (E). Edición de Ramón Valls-Plana, Alianza, Madrid 1997, \$381.

5 Cf. E \$\$ 385-386.

6 Cf. E. Stein, Potenz und Akt. Studien zu einer Philosophie des Seins, en ESGA X, V; "Acto y potencia" (AP), en Obras completas III, V. Tentativa de una determinación de lo espiritual, $\$ \$ 2-4$. 
Pero nuestra filósofa distingue también grados de mayor o menor espiritualidad. Por un lado distingue entre los espíritus creados y el espíritu divino, y sostiene que este último es el único espíritu puro en sentido estricto, pues no está circunscrito a ninguna sustancia limitada y es pura actualidad que fluye desde sí mismo permaneciendo en sí ${ }^{7}$. Es intelecto que conociendo todas las cosas se conoce a sí mismo y voluntad que se quiere a sí misma produciendo y conservando en la existencia todas las cosas, todo ello no por separado sino unido en un único ser espiritual. Entre los espíritus creados, Stein denomina con Santo Tomás de Aquino "espíritus puros" a las creaturas que no tienen cuerpo, como los ángeles y los demonios, y que no obstante son finitas por depender de su creador y por estar circunscritas a sustancias limitadas y distintas de otras sustan$\operatorname{cias}^{8}$. Si bien no hay en ellas oposición de espíritu y materia, sí la hay de potencia y acto, pues hay diferencia de conocimiento y amor entre ellas, en virtud de la cual hay espíritus puros finitos más altos y más bajos. Las potencias de estos espíritus finitos no tienen el sentido de capacidades por desarrollar, sino más bien de la posibilidad de pasar a una actualidad más alta o de un incremento de ser, el cual no se debe a un despliegue de su naturaleza, sino a una intervención sobrenatural por parte de Dios o de otros espíritus finitos más elevados. En este respecto no son inmutables, pero su ser natural se mueve libremente, sin sujeción a ningún obstáculo exterior ni interior.

Según Edith Stein, los espíritus finitos humanos se distinguen de los espíritus puros por su condición de almas esencialmente unidas a un cuerpo, del cual se separan en la muerte, aunque esa separación es del todo antinatural, como lo testimonian el temor a la muerte y las creencias de origen mitológico relativas a fantasmas y aparecidos. En la unidad de la naturaleza humana todo se encuentra subordinado a la ley del espíritu, puesto que el alma espiritual ocupa un lugar central y dominante dentro de esta unidad ${ }^{9}$. Ella le confiere al todo humano el carácter de una personalidad auténticamente individual, haciendo que todos sus niveles están traspasados o penetrados de ese carácter ${ }^{10}$. Pero Stein aclara que no es lo

ESGA XIV, 101 s.; EPH, 675 s.

ESGA XIV, 102 s.; EPH, 677 s.

ESGA XIV, 98 s.; EPH, 672 s.

10 En este punto Edith Stein hace suya la doctrina tomista acerca de la individualidad de Dios y de los ángeles, pero se aparta de su interpretación de la individuación de los seres humanos por la materia signata quantitate: "[...] consideramos a nosotros 
mismo ocupar un lugar central que determinar toda la estructura óntica de la unidad de la naturaleza humana. En ese sentido no se equipara con la forma sustancial de la misma, o sea, con el principio estructural que define al ser del individuo humano como un todo.

\section{AUTOCONCIENCIA Y LIBERTAD}

En Hegel la estructura básica del espíritu es la autoconciencia. La autoconciencia es una forma superior de vida, que se vuelve reflexivamente sobre sí misma, tal como Aristóteles dice de Dios, en un texto del libro XII de su Metafísica que Hegel reproduce en la última página de la Enciclopedia de las ciencias filosóficas ${ }^{11}$. Antes, en el capítulo de la $\mathrm{Fe}$ nomenología del espíritu sobre la Autoconciencia, Hegel había ilustrado el sentido de una conciencia que en su objeto se contempla a sí misma con el ejemplo del reconocimiento. Reconocimiento es lo que ocurre en el vínculo intersubjetivo, pero también en la relación del siervo con el producto de su trabajo, en el que reconoce la huella de su propia actividad formativa, a través de la cual supera su unilateral dependencia de las cosas y del señor para el que las elabora, encontrando una vía de liberación ${ }^{12}$. Esta estructura anticipa y se proyecta hacia el concepto hegeliano del espíritu. El principio subjetivo del yo=yo es reemplazado por el " $y o$ que es nosotros y el nosotros que es yo"13, que constituye una forma realizada de la unidad entre subjetividad y objetividad.

y a los demás, sin tenerlo teóricamente claro, a cada individuo como único en su modo, como Tomás lo exige de los ángeles". AP, 517; "Wir halten uns selbst und die andern, ohne uns darüber theoretisch klar zu sein, jeden einzelnen für einzig in seiner Art, d. h. für eine eigene Spezies, wie es Thomas für die Engel in Anspruch nimmt”. ESGA X, 258. En este aspecto su concepción está más cerca de la haecceitas de Duns Scoto. Cf. W. Redmond, "La rebelión de Edith Stein: la individuación humana”, en Acta fenomenológica latinoamericana, vol. II. Actas del III Coloquio Latinoamericano de FenomenologíalI Coloquio Iberoamericano de Fenomenología y Hermenéutica. CLAFEN, Pontificia Universidad Católica del Perú, Lima/ Sociedad de San Pablo, Bogotá 2005, 89-106.

11 Cf. Aristóteles, Metafísica. Edición trilingüe de V. García Yebra, Gredos, Madrid 1998 (2a. ed.), XII, 7.

12 G.W.F. Hegel, Fenomenología del espiritu (FE). Edición bilingüe de A. G. Ramos, UAM/ Abada, Madrid 2010, 114 ss. (Se cita la paginación de las Gesammelte Werke. Meiner, Hamburg 1968 ss., IX: Phänomenologie des Geistes. Edit. por W. Bonsiepen y R. Heede, consignada en el margen derecho).

13 FE, 108: "Ich, das Wir, und Wir das Ich ist". 
Hegel sostiene que el espíritu es portador de una exigencia práctica o de un mandamiento absoluto en el que se funda la imperatividad de todo mandamiento. Es la exigencia de conocerse a sí mismo ${ }^{14}$. El autoconocimiento al que llama el espíritu no es conocimiento de su realidad empírica en el hombre, sino conocimiento de la esencia universal del ser humano. El fin propio del espíritu es conocerse a sí mismo en todo lo que hay en el cielo y la tierra. Nada pueda permanecerle extraño o ajeno. En tanto que se relaciona consigo mismo en todas las cosas es esencialmente libre, pues la libertad se define para Hegel por el hecho de estar consigo mismo en lo otro. La libertad no es algo que el espíritu pueda tener o no tener, sino que corresponde a su ser más propio. Pero la libertad no es para Hegel mero arbitrio que se opone a la necesidad, sino que es la necesidad que reconoce la razón y realiza la voluntad.

El espíritu se percibe inicialmente como limitado por las cosas del mundo natural y dependiente de ellas. Su tendencia natural es la de liberarse de la sujeción a las realidades ajenas, para lo cual debe actuar sobre ellas imprimiéndoles su propio sello, que es el de la universalidad del pensamiento. Según Hegel, no existe una diferencia esencial ente el pensar y el querer. La voluntad es el mismo pensar en tanto que posee el impulso a darse existencia en el mundo ${ }^{15}$. La voluntad piensa un objeto como fin de su acción y le confiere existencia. Con ello no produce simplemente una realidad externa, sino que cumple su propia esencia, es decir la libertad. Las cosas pierden su exterioridad y extrañeza para el sujeto en la medida que son asimilados por el pensamiento y devueltas al mundo por la voluntad bajo la forma que les ha impreso el pensamiento. De esta manera el mundo natural con el que el hombre se encuentra primeramente pasa a ser un mundo espiritual en el que puede reconocer la huella de su pensamiento y de su acción.

Edith Stein comparte con Hegel la referencia al concepto aristotélico de la vida como base de la autoconciencia:

"Vida significa: estar en movimiento desde el interior. Además vivir espiritualmente significa: ser consciente de este movimiento, ser transparente para sí mismo, ser consciente de sí mismo y eventualmente de otro, intellegere, ponerse en movimiento a sí mismo y a

\footnotetext{
E $\$ 377$.
}

15 FD $\$ 4$. 
otro desde sí mismo. En Dios todo esto es uno y simple, en nosotros es una multitud de diferentes actos" 16 .

Para Stein, la libertad del ser humano radica en el hecho de poder enriquecer la imagen de sí mismo y del mundo a partir de la apertura hacia dentro y hacia afuera en la que consiste la vida espiritual como saber originario acerca del propio ser y de las realidades distintas de sí misma. El hombre no está forzado a este incremento de ser, no está entregado a una relación determinista de estímulos y respuestas, puede seguir o no la invitación que recibe de la realidad propia y de las cosas a adentrarse en su ser, no depende sino de su querer el hacerlo o no. Pero el yo que puede libremente decidirse a hacer u omitir una acción se siente llamado en su interior a hacer algunas cosas y omitir otras. En otras palabras, del poder se deriva la posibilidad del deber, y con ello de ponerse fines y proponerse realizarlos mediante sus actos ${ }^{17}$.

La preocupación por sí mismo de quien no quiere perderse o condenarse, sino salvarse, puede producir el efecto contrario cuando conduce a encerrarse en sí mismo. Con ello se plantea la pregunta acaso el espíritu puede aniquilarse o consumirse. La respuesta a esta pregunta es para Edith Stein tanto un sí como un no ${ }^{18}$. Pervertir el ser espiritual es anularlo, sin poder por ello suprimirlo enteramente. Es lo que ocurre con los condenados y con los demonios, que no dejan de existir por el hecho de corromperse, como ocurre con las realidades materiales. Lo que hay en esos casos es más bien un oscurecimiento y debilitamiento de su ser.

\section{LA FORMACIÓN ESPIRITUAL}

En Hegel, el concepto de formación se presenta de formas distintas pero complementarias. Rara vez lo usa en el sentido habitual, como sinónimo de educación. La idea principal de la que dependen las demás, es que la formación es un principio constitutivo del espíritu como tal, a cuyo movimiento se pliega la formación del individuo. En la Fenomenología del espiritu, aparecida en 1807, Hegel caracteriza todo el libro como un camino de formación de la conciencia humana hacia la ciencia, es decir, hacia el saber verdadero, a partir desde un estado inicial de naturalidad informe, esto es, de un saber que no coincide con la verdad por estar

16 ESGA X, 88; AP, 331.

17 ESGA XIV, 79; EPH, 649.

18 ESGA XIV, 109; EPH, 684. 
mezclado de apariencia. Al camino de formación de la conciencialo describe como un proceso de dolorosa depuración de las apariencias que deforman el saber individual, un camino "de $d u d a$ o, dicho más propiamente, camino de desesperación" ${ }^{19}$. También lo designa como una forma peculiar de historia, "la historia exhaustiva de la cultura como formación de la conciencia misma, hasta llegar a la ciencia” ${ }^{20}$, retomando a su manera una expresión que ya había sido usada anteriormente por Fichte y Schelling. No se trata de la historia real y contingente de hechos culturales ordenados cronológicamente, sino de una cierta elaboración de la misma, que selecciona las concepciones que Hegel considera más relevantes desde el punto de vista del desarrollo de la conciencia, y estructuradas en torno a "configuraciones" que caracterizan las etapas o hitos de este desarrollo. La sucesión de estas figuras obedece, por tanto, a un criterio sistemático que rompe los moldes temporales y responde más bien a un orden de complejidad e implicación crecientes. De este modo, el progreso de una figura a otra significa que la figura anterior es desplazada por la que sigue, sin que ello signifique su pérdida total, sino solamente la negación de su pretensión de ser el saber total que se identifica con la verdad.

Pero para Hegel la historia individual de la conciencia se inserta en un todo más amplio, la historia del desarrollo histórico-cultural de la humanidad que pugna por alcanzar la plena conciencia de sí y con ello la plenitud del verdadero saber. Sin esta referencia, la formación de la conciencia aparece como un movimiento meramente particular, y por tanto unilateral e incompleto" ${ }^{21}$. Dentro del todo de la historia de la humanidad, Hegel se refiere también de un modo más estrecho a una determinada figura de la conciencia o a forma espiritual como período de la formación cultural. Se trata del "Espíritu extrañado de sí", que corresponde principalmente a la Ilustración francesa como una etapa en la que la autoconciencia individual sale de sí para apoderarse del mundo con su pensamiento y conferirle una realidad nueva. La enajenación es el precio que la conciencia paga para acceder a una forma de ser universal, es decir, para que el saber no se quede estancado en la particularidad del

\footnotetext{
19 "[...] als der Weg des Zweifels angesehen werden, oder eigentlicher als der Weg der Verzweiflung [...]". FE, 56.

20 "[...] die ausführliche Geschichte der Bildung des Bewusstseins selbst zur Wissenschaft". Loc. cit.

21 FE, 24.
} 
yo, sino que tenga por objeto la voluntad general, concepto acuñado por Rousseau, que desemboca en la Revolución Francesa con sus luces y sombras. Pero, al revés de Rousseau, Hegel considera que la formación tiene por finalidad sacar al ser humano de la inocencia de su estado natural o la candidez del hombre primitivo:

"El fin racional no es por lo tanto aquella candidez natural de las costumbres ni el goce como tal que en el desarrollo de la particularidad se alcanza con la formación. Consiste, por el contrario, en que la candidez natural, es decir, la pasiva carencia de sí y el primitivismo del saber y el querer, o sea la inmediatez e individualidad en las que está hundido el espíritu, sea elaborada y transformada, y que en primer lugar esta exterioridad suya reciba la racionalidad de que es capaz: la forma de la universalidad, la inteligibilidad [Verständigkeit]"22.

Edith Stein confronta críticamente la idea de formación con el ideal ilustrado de un saber enciclopédico lo más completo posible, al que reemplaza por el de "la configuración que la personalidad humana asume bajo la influencia de múltiples fuerzas formadoras, por ejemplo el proceso de esta formación" ${ }^{23}$. Stein afirma que, por ser espiritual, el alma humana no es solamente forma del cuerpo al que vivifica, sino que tiene también una existencia propia y superior a la del cuerpo. Ella tiene que formarse y gobernarse a sí misma, al mismo tiempo que construye un mundo espiritual en el que pueda vivir y trabajar como en su propio medio. Formar (Bilden) consiste para la filósofa judía en "dar forma (Formen) a un material para que alcance una hechura según su imagen (Bild)" 24 . El material implicado en la formación espiritual son las provisiones externas que le proporcionan los sentidos y la inteligencia y la ca-

22 "Der Vernunftzweck ist deswegen weder jene natürliche Sitteneinfalt noch in der Entwicklung der Besonderheit die Genüsse als solche, die durch die Bildung erlangt werden, sondern dass die Natureinfalt, d.i. teils die passive Selbstlosigkeit, teils die Roheit des Wissens und Willens, d.i. die Unmittelbarkeit und Einzelheit, in die der Geist versenkt ist, weggearbeitet werde und zunächst diese seine Äusserlichkeit die Vernünftigkeit, der sie fähig ist, erhalte, nämlich die Form der Allgemeinheit, die Verständigkeit”. FD $\$ 187$, Obs.

23 "[...] die Gestalt, die die menschliche Persönlichkeit unter der Einwirkung mannigfacher formender Kräfte annimmt, bzw. der Prozess dieser Formung”. E. Stein, "Grundlagen der Frauenbildung", en ESGA XIII, 32; "Fundamentos de la formación de la mujer", en Obras completas IV, 197.

24 "Bilden ist Formen eines Materials zu einem Gebilde, nach einem Bilde". ESGA XVI, “Zur Idee der Bildung” (1930), 44; "Sobre el concepto de formación” (SCF), en Obras completas IV, 187. 
pacidad de sentir estados de ánimo (Gemüt), como fuerza interior que le permite distinguir lo que tiene valor de lo que no lo tiene. Los sentidos y el intelecto proporcionan al alma un mundo de cosas que, en tanto que contribuyen a su alimentación y configuración, son considerados objetos de valor o bienes. Pero si no son asimilados en el interior del alma son mera materia muerta acumulada que no merece ser designada como verdadera formación. El alma que ha ordenado y elaborado racionalmente el material espiritual desde su interior alcanza la paz y la armonía, lo que no quiere decir que se vuelva inactiva, sino todo lo contrario, se ha preparado y ha recibido el estímulo para actuar en conformidad a su propia esencia, demostrando con hechos y obras su eficacia creadora en el mundo exterior ${ }^{25}$.

Stein se pregunta por el sentido de la frase, extraída del plan de enseñanza para maestros católicos del año 1930, que decía que toda formación es autoformación. Es claro que el hombre no puede hacer por sí mismo todo lo que quiere, si es que por "sí mismo" se entiende al sujeto que realiza actos libres que dependen solamente de su voluntad. La naturaleza del ser humano le impone ciertas condiciones que no dependen de su voluntad y que debe respetar si es que no quiere verse "deformado" en vez de formado. Además, el proceso formativo comienza ya en el niño antes de que alcance a hacer uso libre de su voluntad. Pero si el "sí mismo" alude a toda la persona y no solo al sujeto de libre voluntad, entonces es correcto hablar de una autoformación, pues tiene que activar todas sus fuerzas, aunque eso no significa en ningún caso de que la formación dependa únicamente de él, pues requiere también de la cooperación de otros, como sus padres o maestros, que le proporcionan materiales formativos externos necesarios para el proceso. Desde el punto de la fe, es indudable para Edith Stein que también la Providencia divina juega un rol determinante en el camino formativo del ser humano. Ella es la que proporciona la disposición natural llamada a ser desarrollada e incluso puede intervenir con la gracia en el curso de los acontecimientos para que se pueda realizar aquello que la naturaleza no es capaz de producir. La fe aporta también el modelo o arquetipo humano que ha de orientar la formación en la medida que el hombre fue creado a imagen de Dios. Sin embargo, el conocimiento claro y pleno de Dios no es posible para el hombre, de modo que la tendencia interior hacia su imitación puesta

25 ESGA XVI, 42-44; SCF, 185-187. 
por el mismo Dios en cada individuo exige de este un esfuerzo permanente de autocomprensión y de apertura a la Palabra revelada.

\section{ESPÍRITU, COMUNIDAD E HISTORIA}

El concepto hegeliano del espíritu implica una referencia ineludible a la historia de comunidades humanas en las que la libertad se realiza mediante su concreción en costumbres, leyes e instituciones que ponen por obra a la razón en el mundo. Para esta realización de la libertad en tanto que ejercicio de la razón práctica introduce Hegel el neologismo eticidad (Sittlichkeit), en el que recoge las obligaciones que cada individuo tiene hacia la comunidad a la que pertenece. Esas obligaciones se basan en normas y usos ya establecidos, como se desprende de la raíz etimológica Sitte, costumbre. Nacemos en una comunidad que está viva y hacia la cual tenemos obligaciones cuyo cumplimiento la sostiene y mantiene con vida. La libertad se realiza en las comunidades nacionales políticamente organizadas, cuyas instituciones y leyes son justamente la concreción particular de lo universal que está por encima de las limitaciones y arbitrio de los individuos ${ }^{26}$. En este sentido no hay brecha entre deber ser y ser. Es lo que quiere decir Hegel con su famosa frase del Prólogo de la Filosofía del Derecho: "Lo que es racional es efectivamente real, lo que es efectivamente real es racional" 27 .

El concepto de eticidad se refiere precisamente a la libertad que se ha realizado en el mundo, que lo ha modelado conforme a su designio, uniendo lo objetivo, sustancial o universal (el bien) con la voluntad de los sujetos particulares ${ }^{28}$. En esta realidad universal que Hegel llama también espíritu de un pueblo, no pretende que el individuo esté anulado, sino todo lo contrario, pues la comunidad es el lugar en que cada uno realiza su libertad en la medida en que es reconocido como sujeto libre y a la vez reconoce la libertad de los otros ${ }^{29}$. La libertad efectiva presupone el reconocimiento mutuo y la interacción de muchos hombres

\footnotetext{
26 FD $\$ 144$.

27 "Was vernünftig ist, das ist wirklich; und was wirklich ist, das ist vernünftig". Werke VII, Vorrede, 24; FD, Prólogo, 18. Corrijo la traducción de wirklich, cuyo sentido no queda adecuadamente recogido con la expresión "real".

28 FD $\$ 145$.

29 FD $\$ 147$.
} 
libres que emprenden una obra común y toman conciencia de sí como un "nosotros".

La comunidad ética no es para Hegel una simple suma o agregado de individuos, sino un organismo que se articula en distintos niveles de desarrollo: la familia, la sociedad civil y el Estado. Con Hegel por primera vez la sociedad civil ya no comprende al Estado en su globalidad, sino únicamente aquel momento en el proceso de su formación que corresponde al sistema económico organizado para la satisfacción de las necesidades de los hombres. El Estado, en cambio, tiene su fin en sí mismo y supera toda forma de asociación que esté solamente al servicio de fines particulares.

"Cuando se confunde el Estado con la sociedad civil y es determinado sobre la base de la seguridad y protección personal, el interés del individuo en cuanto tal se ha transformado en el fin último [...] Su relación con el individuo es sin embargo totalmente diferente: por ser el estado el espíritu objetivo, el individuo solo tiene objetividad, verdad y ética si forma parte de él. La unión como tal es ella misma el verdadero fin y contenido, y la determinación de los individuos es llevar una vida universal. Sus restantes satisfacciones, actividades y modos de comportarse tienen como punto de partida y resultado este elemento sustancial y universalmente válido"30.

El Estado tiene derecho a pedir a los ciudadanos el sacrificio de sus bienes mediante impuestos y de la misma vida, en caso de guerra, todo lo cual no puede ser justificado por las doctrinas contractualistas -según las cuales el Estado nace de un acuerdo que los mismos contrayentes pueden disolver cuando les parezca- y las doctrinas eudemonistas, en las que el fin supremo del Estado es el bienestar de los súbditos. Hegel rechaza también las teorías que quieren imponerle límites al Estado sujetándolo a normas de derecho internacional, que considera una

30 "Wenn der Staat mit der bürgerlichen Gesellschaft verwechselt und seine Bestimmung in die Sicherheit und den Schutz des Eigentums und der persönlichen Freiheit gesetzt wird, so ist das Interesse der Einzelnen als solcher der letzte Zweck zu welchem sie vereinigt sind [...] Er hat aber ein ganz anderes Verhältnis zum Individuum; indem er objektiver Geist ist, so hat das Individuum selbst nur Objektivität, Wahrheit und Sittlichkeit, als es ein Glied desselben ist. Die Vereinigung als solche ist selbst der wahrhafte Inhalt und Zweck, und die Bestimmung der Individuen ist, ein allgemeines Leben zu führen; ihre weitere besondere Befriedigung, Tätigkeit, Weise des Verhaltens hat dies Substantielle und Allgemeingültige zu seinem Ausgangspunkte und Resultate”. FD $\$ 258$, Obs. 
abstracción carente de efectividad. El Estado es también el sujeto que protagoniza la historia universal, la cual concibe como una especie de tribunal que juzga acerca de la idoneidad de los pueblos para liderar el proceso de desarrollo de la conciencia de la libertad y su realización ${ }^{31}$.

En su concepción de las comunidades humanas, Edith Stein está más cerca de la posición de Hegel que de la de quienes, como Dietrich Hildebrand, consideran que las comunidades no son organismos, puesto que sus partes $-\mathrm{O}$ sea los individuos humanos- son anteriores al todo. Esta tesis solo es válida, a su juicio, para las comunidades particulares, e incluso en estas merece una revisión ${ }^{32}$. El mismo concepto de humanidad, que engloba todas las comunidades humanas, tanto las efímeras como las permanentes, no es para ella solamente un concepto genérico referido al conjunto de lo que es hombre, sino el concepto de un individuo concreto, o de un organismo corporal-espiritual. No obstante, lo que Stein quiere decir no es que en la humanidad el todo sea anterior a las partes, sino más bien que la humanidad está presente en todo hombre individual, y que por lo tanto comienza también con el primer hombre.

Stein está de acuerdo con Hegel en describir la historia como un proceso de desarrollo espiritual. Sin embargo, no acepta que lo que se desarrolla en este proceso sea la libertad, porque, a su juicio, la libertad en sentido estricto no es algo que pueda desplegarse o desarrollarse. Lo que se desarrolla no es la libertad, sino su portador: la persona individual o la comunidad de personas. Stein considera que Hegel apunta a lo mismo cuando habla de un desarrollo del espíritu hacia la conciencia de su libertad. Pero no admite que el contenido de la historia se resuma en esta autoposesión del espíritu o la persona. Tampoco admite como necesidad de principio que esta autoposesión de la libertad exija como condición indispensable la mediación de la comunidad y su organización superior, que es el Estado, aunque no niega que esta relación de hecho se dé33. Pero objeta explícitamente lo que denomina "la doctrina política del Idealismo Alemán”, según la cual el Estado es el “instrumento

FD, \$\$ 341-342.

32 ESGA XIV, 136; EPH, 716.Cf. D. v. Hildebrand, Metaphysik der Gemeinschaft, Haas\&Grabherr, Augsburg 1930.

33 E. Stein, Eine Untersuchung über den Staat”, en ESGA VII, 123 s.; "Una investigación sobre el Estado" (ISE), en Obras Completas II, 645. 
que permite establecer el dominio de la ley moral en el mundo"34. A su juicio, el derecho puede considerarse a lo sumo como condición previa de la moralidad en la medida que de facto puede remover obstáculos a los motivos morales y educar para la moralidad, pero que ello no es algo prescrito necesariamente por su propia estructura.

\section{ESPÍRITU Y RELIGIÓN}

Hegel acepta la pretensión ilustrada de dar cuenta racional del contenido de la religión, pero con el romanticismo rechaza que la filosofía reduzca este contenido a la abstracción de un ser supremo que no se revela ni se relaciona efectivamente con el hombre en la historia. Por eso mismo considera necesario definir a Dios como espiritu absoluto, al que le es esencial salir de sí y manifestarse al hombre ${ }^{35}$. La religión es saber del espíritu de Dios acerca de sí mismo a través de la mediación del espíritu finito del hombre, que pasa por las etapas históricas de desarrollo correspondientes al mundo oriental (religión inmediata o de la naturaleza), los mundos griego y judío (religiones de la belleza y la sublimidad), el mundo romano (religión de la finalidad) y culmina con el cristianismo (religión consumada) ${ }^{36}$. Lo que le confiere a la religión cristiana superioridad definitiva sobre todas las demás religiones es, según Hegel, justamente el hecho de que en ella Dios se revela a sí mismo como espíritu.

La interpretación del verdadero sentido de espíritu le compete, sin embargo, a la filosofía y no a la religión, que carece de los instrumentos conceptuales adecuados para ello. El elemento en el que se mueve la fe es, según Hegel, la representación, una forma primera de darse Dios objetivamente en la conciencia, asociada al sentimiento, la imaginación y la narración ${ }^{37}$. Frente a esa forma inicial se yergue el pensar como forma

34 "Die Staatslehre des deutschen Idealismus betrachtet den Staat als das Werkzeug um das Sittengesetz in der Welt zur Herrschaft zu bringen”. ESGA VII, 122; ISE, 643 s. En realidad, al menos en el caso de Hegel, no es exacto hablar del Estado como un "instrumento", sino más bien como de una totalidad espiritual.

$35 \mathrm{E} \$ 564$.

36 Cf. G.W. F. Hegel, Vorlesungen über die Philosophie der Religion, I-III. Edit. por W. Jaeschke, Meiner, Hamburg 1983-1985; Lecciones sobre filosofía de la religión I-III (LFR). Edición de R. Ferrada, Alianza, Madrid 1984-1987, II, La religión determinada, según la lección de 1827.

37 Cf. LFR I, 277-281 (111-114, 106 s. del texto original). 
superior. Pero a su vez hay que distinguir el pensar meramente reflexivo o del entendimiento, que queda fijado en las oposiciones del pensamiento finito, del pensar especulativo, que es el propiamente filosófico, pues aprehende la unidad de los opuestos ${ }^{38}$.

Por otra parte, Hegel rechaza la concepción romántica del sentimiento religioso como lugar de la presencia real de Dios y fuente de todas las manifestaciones humanas, de donde se seguiría la subordinación de la filosofía a la religión. Aunque acepta que la religión tiene en principio un componente de sentimiento, lo que verdaderamente importa para él es su contenido objetivo, que no brota del sentimiento, sino que, por el contrario, determina a este y lo purifica de modo que pueda orientarse por el movimiento absoluto del espíritu. Quien hace del sentimiento el fundamento de la religión, comete, según Hegel, el error de someterla a la indeterminación y el arbitrio subjetivos. Por otra parte, la religión es esencialmente liberadora, lo que es incompatible con el sentimiento de dependencia defendido por Schleiermacher, el cual sería mejor representado por un perro que por un ser humano ${ }^{39}$.

Edith Stein presenta al menos dos grandes coincidencias con respecto a la consideración hegeliana de la religión, que se encuentran documentadas al comienzo de la sección novena de su Estructura de la Persona Humana. La primera de ellas es el procedimiento ontológico en virtud del cual el ser finito del hombre remite al ser infinito de Dios:

"Es característico de todo lo finito el hecho de que no puede ser comprendido exclusivamente por sí mismo, sino que remite a un primer ser que hemos de considerar infinito, o, más correctamente al ser infinito, porque el ser infinito solo puede ser Uno. A este ser primero e infinito le damos el nombre de Dios, dado que sus atributos están en correspondencia con nuestra idea de Dios" ${ }^{\prime 40}$.

38 Cf. E \$\$ 79-82.

39 Cf. G.W.F. Hegel, "Vorwort zu H.W.F. Hinrichs, Die Religion” (1822), en GW XV, 137; "Prólogo a Hinrichs" (1822), en Escritos sobre religión. Edición de G. Amengual, Sígueme, Salamanca 2013,104 s.

40 " $\mathrm{Zu}$ allem Endlichen gehört es, dass es nicht aus sich allein begriffen werden kann, dass es auf ein erstes Seiendes zurückgreift, das ein Unendliches sein muss oder richtiger: das Unendliche, weil das Unendliche nur eines sein kann. Wir nennen dieses erste, unendlich Seiende, weil seine Attribute unserer Gottesidee entsprechen". ESGA XIV, 159; EPH, 742. 
La segunda coincidencia se refiere a la centralidad que tanto Stein como Hegel le confieren al sentido de la revelación, aunque, por otra parte, se distinguen radicalmente en la forma de entenderla. La filósofa judía sostiene, en continuidad con la tradición del pensamiento cristiano, que el entendimiento humano finito no puede responder por sí solo las preguntas fundamentales acerca del origen del mundo, del género humano y de los individuos, por lo que la respuesta debe ser ofrecida por un espíritu para el que sea asequible lo que está fuera del alcance del entendimiento humano. La revelación es justamente el desvelamiento de aquello por parte de Dios para el hombre. La diferencia con Hegel no se refiere primordialmente al contenido de la revelación, sino a su relación con la filosofía. El contenido es resumido por Edith Stein de un modo que Hegel seguramente no objetaría: el hombre ha sido creado por Dios, a su imagen y semejanza, es libre y responsable de aquello en lo que se convierta, pero puede y debe hacer que su voluntad esté en consonancia con la voluntad de Dios ${ }^{41}$.

Las diferencias con Hegel se empiezan a notar cuando Stein, al igual que Santo Tomás de Aquino, niega que todas las verdades reveladas puedan ser comprendidas por la sola fuerza de la razón humana. Para ella son parte esencial de la religión cristiana los misterios, a los que solo se accede con ayuda del don sobrenatural de la fe. Si Dios ha levantado un poco el velo que oculta sus secretos, es porque el hombre los necesita para la vida a la que ha sido llamado. Pero el concepto hegeliano de la fe no admite que nada quede oculto a la razón, pues para el filósofo suabo ello equivaldría a sostener que Dios se guarda sus secretos por envidia del saber humano.

"[...] hay, sin duda un misterio, pero no en el sentido de que no se lo sepa. Es un secreto para la conciencia de tipo intelectual, para el conocimiento sensible, pero es algo manifiesto para la razón. Cuando se toma en serio el nombre de Dios, entonces, ya según Platón y Aristóteles, Dios no es algo tan envidioso como para que no se comunique" ${ }^{42}$.

ESGA XIV, 160; EPH, 743.

42 "[...] allerdings ein Mysterium, aber nicht in dem Sinn, dass man es nicht wisse. Dem verständigen Bewusstsein, der sinnlichen Erkenntnis ist es ein Geheimnis, der Vernunft ist ist es ein Offenbares. Wenn es Ernst mit dem Namen Gottes, so ist schon nach Plato und Aristoteles Gott nicht neidisch, dass er sich nicht mitteilte”. LFR I, 263 (201). 


\section{CONCLUSIONES}

Edith Stein no es lectora habitual de Hegel, ni está significativamente influida por él. Aunque se refiere a su concepción acerca de la historia y el Estado, prácticamente no cita ninguno de sus libros. En su Autobiografía menciona que Adolf Reinach puso en sus manos un ejemplar de la Fenomenología del espíritu para que se entretuviera mientras él le revisaba un manuscrito, pero añade que la emoción que la embargaba esperando el veredicto sobre su obra le impidió concentrarse en esa lectura ${ }^{43}$. No obstante, es posible constatar importantes puntos de encuentro entre ambos pensadores. Tanto Hegel como Edith Stein se refieren al espíritu como lo que define esencialmente al ser humano, diferenciándolo de la realidad material y de la vida vegetal y animal. Ambos entienden, además, que lo propio del espíritu no se reduce a la capacidad de conocer o de razonar, sino que implica también la capacidad de salir de sí, de trascender los límites de su ser finito y abrirse al otro, que incluye a otros seres espirituales finitos, pero sobre todo al espíritu infinito, el Absoluto o Dios.

Además de la común raíz cristiana, Hegel y Edith Stein comparten una fuente socrática y aristotélica. La fuente socrática se expresa principalmente en el imperativo espiritual del autoconocimiento, y la aristotélica tiene múltiples aspectos, entre los cuales cabe destacar, para efectos de esta exposición, el concepto de la vida, asociado a la actividad del alma, y el relieve de la comunidad como el lugar en que la acción humana se despliega superando los particularismos egoístas.

Otro punto de encuentro muy importante entre la concepción de Hegel y de Stein sobre el espíritu se refiere a la centralidad que los dos le confieren al proceso de su formación. Ambos tienen muy claro que la formación no consiste en la mera adquisición y posesión de múltiples conocimientos exteriores, sino en la configuración espiritual del ser humano. Es digno de destacar el hecho de que Edith Stein comience su Estructura de la persona con una referencia histórica al valor que el idealismo alemán asignaba al concepto de humanidad en el sentido de la perfección a la que está llamada a servir la educación, al mismo tiempo que reconoce el retroceso experimentado por esta forma de pensar, que culminó en un gran fracaso al estallar la I Guerra Mundial ${ }^{44}$.

43 Cf. ESGA I, 230 s.; Obras completas I, 384 s.

44 ESGA XIV, 3 s.; EPH, 563 s. 
A pesar de estas afinidades de fondo no es menos cierto que existen también entre nuestros dos filósofos diferencias profundas, algunas de las cuales son insalvables. Entre las que conciernen más directamente a la concepción del espíritu encontramos, en primer lugar, el modo como ambos se refieren a la relación entre espíritu y naturaleza y a la relación entre libertad e historia. Aunque Hegel rechaza la imputación de panteísmo que frecuentemente se le ha hecho y todavía se le hace ${ }^{45}$, no es menos cierto que su sistema de filosofía, basado en el principio de la identidad de los contrarios, si bien no anula las diferencias, no admite un más allá (Jenseits), una trascendencia del espíritu respecto de la naturaleza, ni un conocimiento sobrenatural que sobrepase las capacidades de la razón, como lo plantea Edith Stein siguiendo a Tomás de Aquino.

Asimismo, hay una gran divergencia en lo que concierne al sentido del Estado y su rol respecto de la moral. Stein no puede aceptar que el Estado sea la instancia determinante de la realización de la libertad, y con ello de la vida ética de los individuos y la comunidad, como sostiene Hegel. En otras palabras, no está dispuesta a delegar en la actividad del Estado el impulso fundamental para la plena realización espiritual del ser humano, que en último término no puede depender de otro poder que el de Dios.

No cabe duda que estos planteamientos de dos grandes expositores de la tradición metafísica de inspiración cristiana constituyen un desafío siempre abierto para la reflexión de quienes se consideran herederos de esa misma tradición y desean actualizarla a la luz de los dilemas espirituales contemporáneos.

$\overline{45}$ Cf. por ejemplo, E\$ 573. 
